\title{
Sedimentary facies and sequence stratigraphy in the Lower Triassic Jialingjiang Formation, Sichuan Basin, China
}

\author{
Chunyan Sun ${ }^{1,2,3} \cdot$ Mingyi Hu $u^{1,2,3} \cdot$ Zhonggui Hu$u^{1,2,3} \cdot$ Ngong Roger Ngia ${ }^{1,2,3,4}$
}

Received: 1 February 2018 / Accepted: 10 September 2018 / Published online: 25 September 2018

(c) The Author(s) 2018

\begin{abstract}
The Lower Triassic Jialingjiang Formation is an important oil and gas exploration target in the Sichuan Basin. The lithofacies mainly consists of clastic rocks, carbonates, and evaporates, which represents a transition from continental to marine depositional environment. The Jialingjiang Formation of the Sichuan Basin is a typical epeiric carbonate platforms. The study area contains four types of facies, including mixed tidal flat facies, open platform facies, restricted platform facies, and evaporitic platform facies. Based on the analysis of cores and logging data, two types of type II sequence boundaries were identified, which are, respectively, local exposure unconformity boundary and lithology and lithofacies transformation boundary. The Jialingiiang Formation is divided into three third-order sequences and six system tracts. Thus, we establish a connected multi-well sequence stratigraphic framework based on typical single-well sequence stratigraphic division. The sedimentary evolution of the Jialingjiang Formation was divided into three major sedimentary periods and six stages, with rising and falling of the sea level, mixed tidal flat, open platform, and restricted platform prograded first, and then restricted platform and evaporitic platform retrograded. It also shows that the open platform shoal and restricted platform tidal flat have oolitic limestone and algal dolomite with good-quality physical properties and are the favorable reservoir facies belt for hydrocarbon exploration and development.
\end{abstract}

Keywords Carbonate platform $\cdot$ Third-order sequence $\cdot$ Sedimentary evolution $\cdot$ Jialingjiang Formation $\cdot$ Sichuan Basin

\section{Introduction}

In recent years, oil and gas exploration in the Lower Triassic marine strata in the Sichuan Basin has made a significant progress. Many scholars have studied the carbonate reservoirs in different basins, and found that the carbonate rocks in the Lower Triassic of Sichuan Basin have large thickness and good-quality physical properties, and favorable

Mingyi $\mathrm{Hu}$

humingyi65@163.com

1 Sedimentary Basin Research Center, Yangtze University, Wuhan City 430100, Hubei Province, People's Republic of China

2 Hubei Cooperative Innovation Center for Unconventional Oil and Gas, Yangtze University, Wuhan 430100, Hubei, People's Republic of China

3 School of Geosciences, Yangtze University, Wuhan 430100, Hubei, People's Republic of China

4 Department of Geology, University of Bamenda, Bambili-Bamenda, Cameroon environmental conditions of potential oil and gas reservoirs (Enos and Sawatsky 1981; Read 1985; Mzzullo and Harris 1992; Mancini and Benson 1998; Thanguay and Friedman 2001; Ehrenberg 2006; Li et al. 2008; Harris 2010; Tan et al. 2011; Jiang et al. 2014; Wang et al. 2015; Li 2016). Medium-to-large-sized gas reservoirs such as those of Duhekou, Yuanba, Puguang, and Tianshanpo, have been found in the central and eastern part of the Sichuan Basin ( $\mathrm{Li}$ et al. 2008; Jiang et al. 2014; Li 2016). Carbonate platforms include ramps, rimmed platforms, epeiric platforms, isolated platforms, and drowned platforms with their own categories (Read 1985) and homoclinal ramp, distally steepened ramp, non-rimmed shelf, and rimmed shelf (Pomar 2001). The Jialingjiang Formation of the Sichuan Basin is a typical epeiric carbonate platforms. Studies of the Jialingjiang Formation have primarily focused on paleontology, lithofacies palaeogeography, and reef and shoal reservoir (Tan et al. 2011; Wang et al. 2015). However, there are significant discrepancies between sequence stratigraphic divisions of this formation among individual fields. In this paper, we make a clarification of the sequence stratigraphic characteristics 
and spatial distribution of sedimentary facies, and explain the evolution of the Jialingjiang Formation in detail based on cores from 18 wells and 5 outcrop profiles. The purpose of this study is to describe the internal sequence structure and sedimentary system of the Jialingjiang Formation in the Sichuan Basin and to predict the distribution of favorable hydrocarbon reservoirs.

\section{Geologic setting and stratigraphy}

The Sichuan Basin is a large Paleozoic and Meso-Cenozoic marine and continental basin within the Sichuan depression of the Yangtze paraplatform, covering an area of about $260,000 \mathrm{~km}^{2}$. As a result of taphrogeny, there exist multiple basalts and diabase flows along the Huayingshan Fault besides Liangping and Kangdian area. The Sichuan Basin was converted into a large depression during the Indosinian orogenic movement, while folding and uplift occurred frequently during the late Yanshan movement (Tian 1989; Wang et al. 2015). The structural pattern of the basin is dominated by two NE-SW and NW structural lines, forming a typical diamond-shaped basin (Fig. 1).

During the Early Triassic period, the periphery of the basin has not changed greatly, and the basin remained relatively deep in the east and shallow in the west. The Jialingjiang Formation can be divided into five lithologic sections in stratigraphic order, namely $\mathrm{T} 1 \mathrm{j} 1-\mathrm{T} 1 \mathrm{j} 5$. The first and third sections (T1j1 and $\mathrm{T} 1 \mathrm{j} 3$ ) are composed of micritic limestone, bioclastic limestone, and oolitic limestone, while the second, fourth, and fifth sections $(\mathrm{T} 1 \mathrm{j} 2, \mathrm{~T} 1 \mathrm{j} 4$, and $\mathrm{T} 1 \mathrm{j} 5)$ are composed of dolomite, gypsum, and evaporite-solution breccia. With accretion of the adjacent platform, the basin shallowed. Limestone, dolomite, gypsum, and halite developed across a majority of the basin producing two vertical assemblages of limestone-dolomite-gypsum and halite, whereas, in the northwestern margin of basin, the $\mathrm{T} 1 \mathrm{j} 1$ and $\mathrm{T} 1 \mathrm{j} 2$ facies transition, and mainly form gray-brown and purplish red micrite limestone. During the Jialingjiang period, oolitic shoals, bioclastic shoals, and calcarenite shoals were widely distributed throughout the basin. These lithofacies become favorable locations for oil and gas accumulation

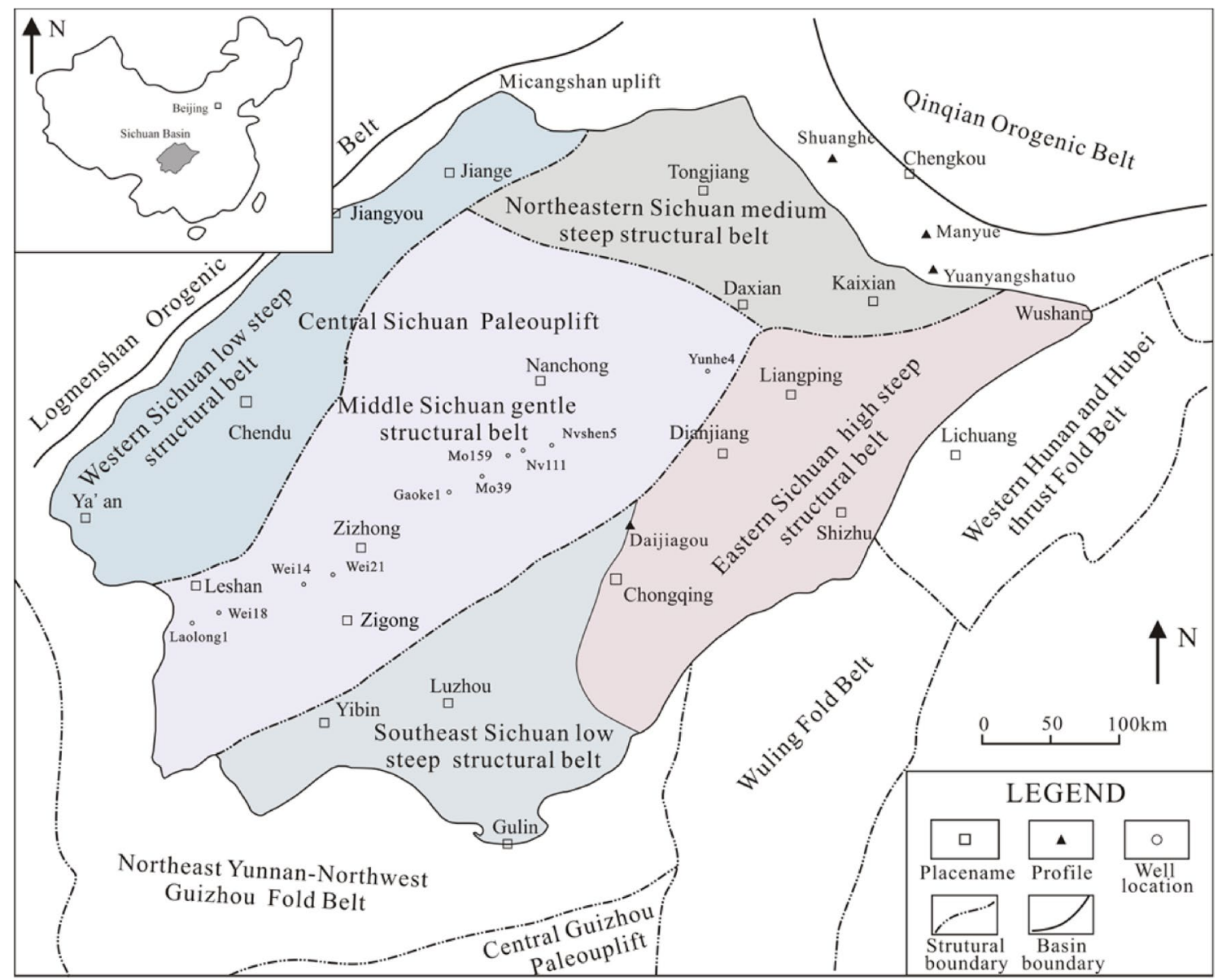

Fig. 1 Simplified structural subdivisions of the Sichuan basin 
during post-depositional diagenesis (Tian 1989; Tan et al. 2011).

\section{Sedimentary facies analysis}

Based on the detail observation and description of the 18 drilled cores of the research area and the outcrop section data, it is concluded that the Jialingjiang Formation is composed of clastic rocks, carbonates, and evaporates. The carbonates are widely distributed in the basin, while the evaporites and clasolites are sparsely distributed. According to facies markers, primary sedimentary structures, and facies sequences, the Jialingjiang Formation mainly is a carbonate platform deposits (Read 1985). Through the facies analysis, especially for microfacies analysis (Flügel 2010), the depositional model of the Jialingjiang Formation is built (Fig. 7).

\section{Mixed tidal flat facies}

The main lithofacies of the mixed tidal flat facies includes sandstone, mudstone and other clastic rocks developed in the $\mathrm{T} 1 \mathrm{j} 1$ and $\mathrm{T} 1 \mathrm{j} 2$ lithologic sections (Fig. 2a). The mixed tidal flat facies can be divided into two subfacies, which are, respectively, the supertidal flat and intertidal flat. In addition, there can be further subdivided into three microfacies, which are sand flat, gypsum flat, and mud flat.

Mixed tidal flat facies is characterized by a combination of carbonates and terrigenous clastic rocks. The sedimentary environment is euxinic and the salinity is high. The mixed facies tidal flat is sparsely distributed in southwestern margin of basin near the source of terrigenous debris from the west Sichuan central Yunnan oldland and Longmenshan orogenic belt. This variation is presumed to the result of frequent sea-level change, source supply change, and palaeoclimatic change.

\section{Restricted platform facies}

The restricted platform facies deposits are mainly composed of light gray dolomitic limestone, muddy-silty dolomite, and gypsum dolomite (Fig. 2b-d). This facies is divided into three subfacies, including restricted tidal flat, restricted lagoon, and intraplatform shoal. The restricted tidal flat can be further subdivided into three microfacies, including dolomite flat, limy dolomite flat, and muddy dolomite flat. The restricted lagoon is subdivided into six microfacies, including micrite limestone, dolomite-bearing limestone, pellet micritic limestone, gypsum and dolomite-bearing micrite limestone, leopard porphyritic lime dolomite, and micritic shell limestone (Flügel 2010). The intraplatform shoal is subdivided into four microfacies, including oolitic limestone, biological debris limestone, calcirudite, and micritic limestone.

Restricted platform facies corresponds to a carbonate depositional environment with little terrigenous material. This facies has slightly lower wave energy and relatively higher salinity comparing with the open platform facies. Slightly rise or fall of relative sea level would cause a large area of the platform subarial exposure, which results in the development of the restricted platform tidal flat. Carbonate grains are prone to occur penecontemporaneous dolomitization under the action of the surface water with high salinity and rich magnesium. The widespread development of tidal flat dolomite is a critical indicator of restricted platform environment in the study area. These facies are developed in the $\mathrm{T} 1 \mathrm{j} 2, \mathrm{~T} 1 \mathrm{j} 4$, and $\mathrm{T} 1 \mathrm{j} 5$ lithologic sections.

\section{Open platform facies}

The main sediment of the open platform facies is dolarenite, bioclastic bearing limestone and micritic limestone (Fig. 2e-g). This facies contains two types of subfacies, which are intraplatform shoal and open subtidal zone. The subfacies can be divided into four microfacies, which are oolitic limestone, biological debris limestone, calcirudite, and bioclastic limestone and micritic limestone. The intraplatform shoal is mainly composed of light gray, mediumthick-bedded oosparite with wedge cross bedding, and sparry bioclastic oolitic limestone with trough cross bedding (Fig. 2h). The characterizations of the open subtidal zone contain bioclastic limestone and micritic limestone with horizontal bedding (Fig. 2i, j).

Deposition of the open platform facies occurred during relative sea-level rise with normal marine salinity, and which mainly developed in the $\mathrm{T} 1 \mathrm{j} 1$ and $\mathrm{T} 1 \mathrm{j} 3$ lithologic sections. The intraplatform shoal is formed near relatively high area with strong hydrodynamic conditions, and the reservoir properties of which are relatively good. The open subtidal zone was deposited under weak hydrodynamic conditions and distributed among shoals sediments, and the reservoir properties of which are relatively poor.

\section{Evaporitic platform facies}

The main lithofacies of the evaporitic platform facies includes gypsum-bearing dolomite, gypsum, and gypsumbearing micrite dolomite (Fig. 2k, 1), and it can be subdivided into two subfacies, which are evaporitic lagoon and evaporitic tidal flat. The evaporitic lagoon can be further subdivided into two microfacies, which is gypsum lagoon and dolomite lagoon. The evaporitic tidal flat contains three

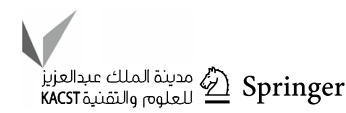



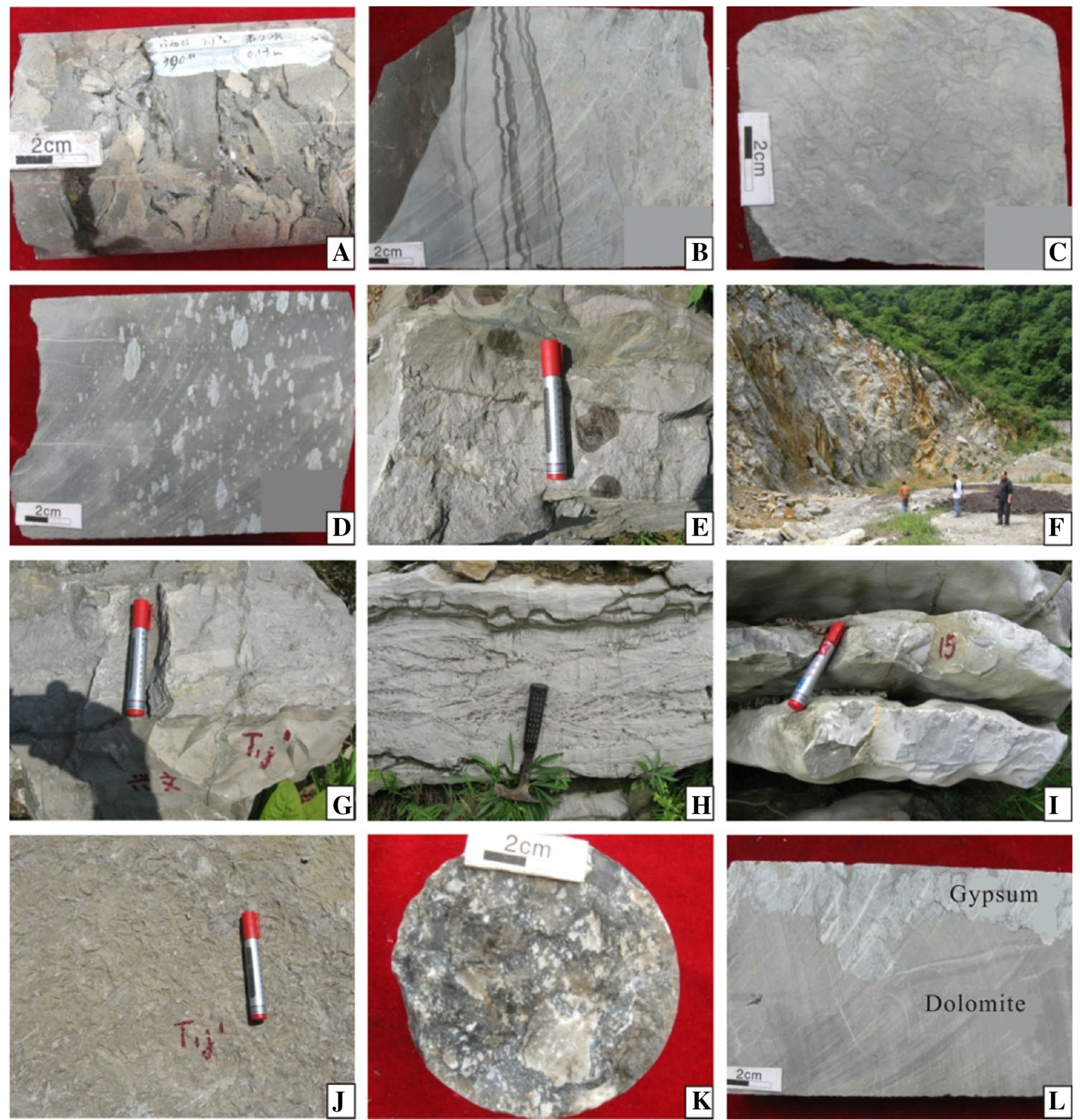

Fig. 2 Photographs of the profiles and cores: a Gypsum breccias, Menxi 8, T1j4; b light gray taupe limestone, Tiexi 1, T1j1; c muddysilty dolomite, Tiexi1, T1j2; d micritc gypsum dolomite, bird-eye structure, Tiexi 1, T1j2; e bioclastic-bearing limestone, Xingwenwangchengpo Profile, T1j1; f light gray micritic limestone, Wazidian Profile, T1j1; g dolarenite, Xingwenwangchengpo Profile, T1j1;

microfacies, which are respectively gypsum dolomite, gypsum mudstone, and dolomite-bearing gypsum.

The environment of the evaporitic platform facies was developed relatively restricted compared to the restricted h sparry bioclastic oolitic limestone, pinnate cross bedding, T1j1; i vermicular limestone, Wadianzi Profile, $\mathrm{T} 1 \mathrm{j} 1 ; \mathbf{j}$ biological trace fossil-bearing micritic limestone, Xingwenwangchengpo Profile, T1j1; k gypsum-bearing dolomite, Chi 63, T1j2; l Gypsum-bearing micrite dolomite, Tiexi 1, T1j2

platform period and under arid-type climate where evaporation was strong, causing the extensive development of evaporites. However, frequent seawater flooding developed a thin-bedded penecontemporaneous gypsum-bearing 

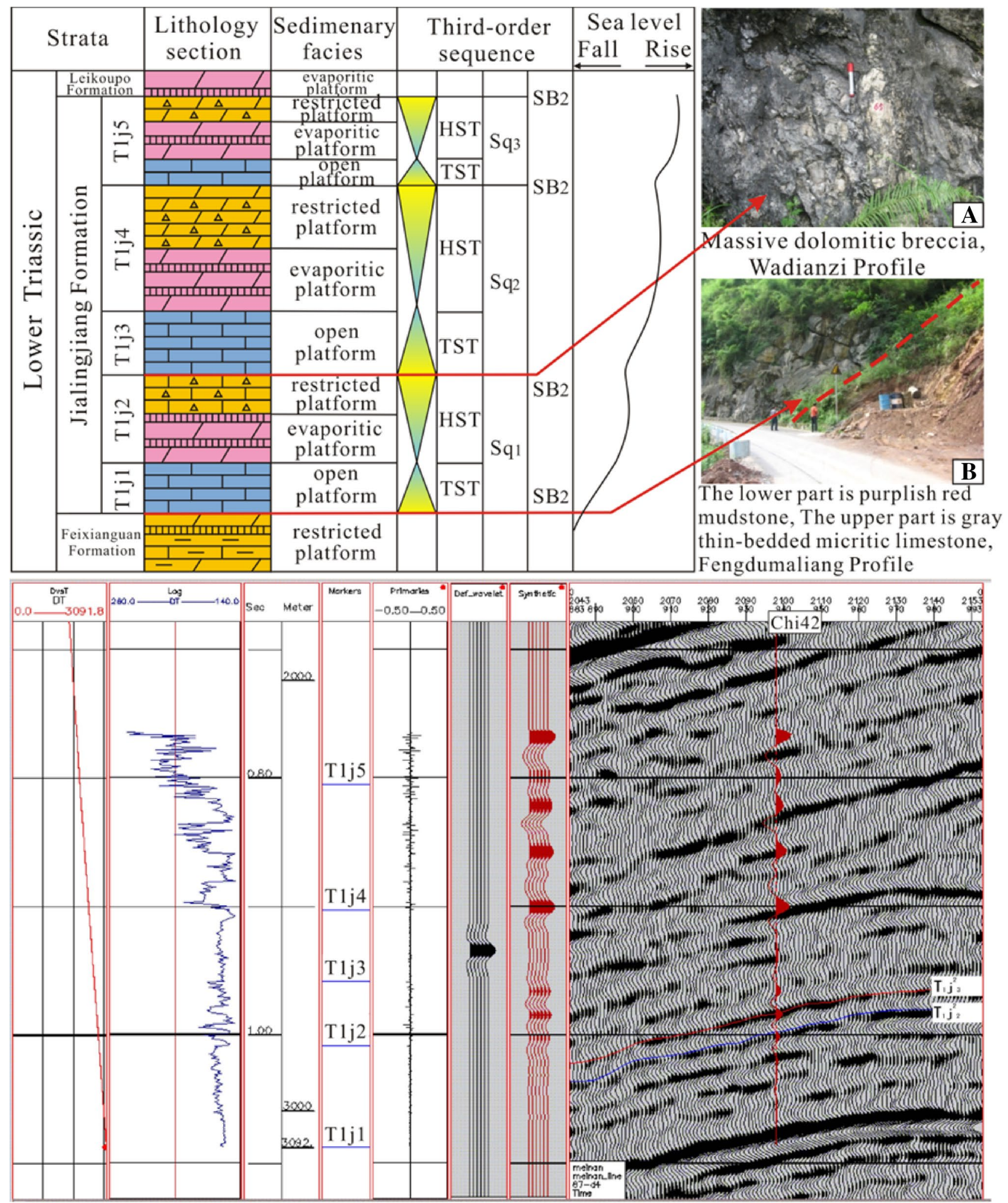

Fig. 3 Sequence stratigraphic divisions in the Jialingjiang Formation 


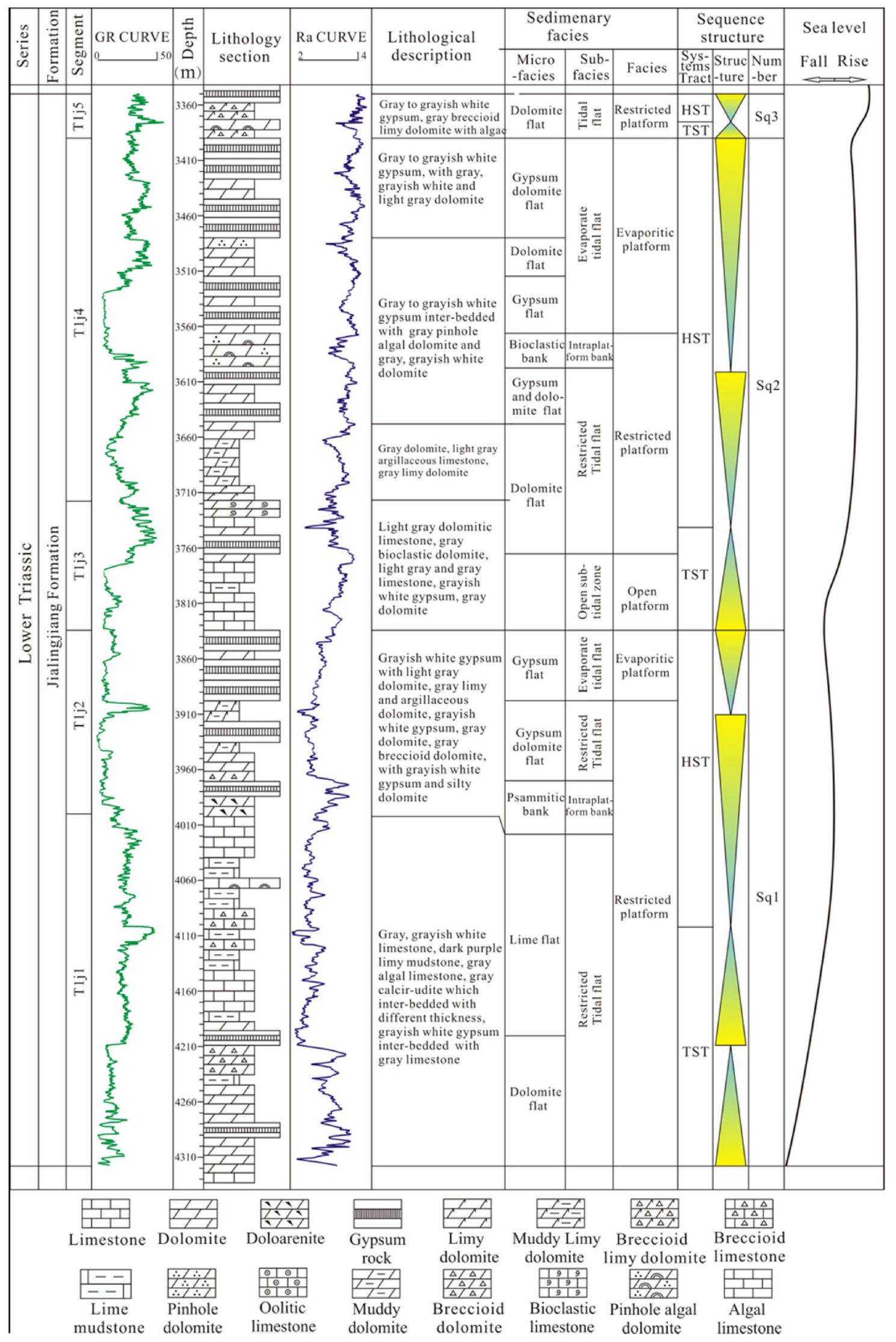


४Fig. 4 Sequence stratigraphic and sedimentary facies characteristics of Well She1 in the Jialingjiang Formation ( $G R$, natural gamma logging; $R a$, apparent resistivity logging)

dolomite and gypsum-bearing mudstone. The evaporites are mainly distributed in the $\mathrm{T} 1 \mathrm{j} 2, \mathrm{~T} 1 \mathrm{j} 4$, and $\mathrm{T} 1 \mathrm{j} 5$ lithologic sections.

\section{Sequence stratigraphic characteristics}

\section{Sequence boundary}

Many scholars have worked on sequence stratigraphic application to hydrocarbon exploration (Vail et al. 1977; Thanguay and Friedman 2001). In accordance with their theories and based on the comprehensive study of seismic and logging data, we identified two types of sequence boundary, which includes unconformity boundary and the transformation boundary of lithology and lithofacies transformation boundary. According to the well and seismic calibration of synthetic records, it is indicated that the well has a good correspondence with the seismic profile (Fig. 3).

\section{Unconformity boundary}

Different types of sequence boundaries are formed in exposed areas along the basin margin. The sediment characteristics of these boundaries depend on the length of depositional hiatus and other related effects. During the Jialingjiang period, a set of shallow-water carbonate platform facies were deposited. A number of high-energy shoals are developed in Sichuan Basin. These shoals occurred during relative sea-level fall and mark the unconformity surface. In the study area, the unconformity boundary is mainly characterized by local exposure and erosion, and dolomitization of shoals and evaporitic supertidal flat. In the top most of the $\mathrm{T} 1 \mathrm{j} 2$ lithologic section, massive karst-collapse dolomitic breccias is developed, which is an important indicator for exposure and dissolution along an unconformity surface (Fig. 3a).

\section{Lithology and lithofacies transformation boundary}

Relative sea-level fluctuation can create or destroy sediment accommodation space. Lithology and lithofacies of sediments obviously vary throughout each transgressive and regressive cycle. The top most of the Feixianguan Formation (Fig. 3b) is clearly defined by restricted platform facies with fuchsia calcareous mudstone, while the lowermost of the Jialingjiang Formation is clearly defined by open platform facies with gray thin-bedded micritic limestone (Fig. 3b). This transition represents a lithology and lithofacies transformation boundary. Fuchsia calcareous mudstones of restricted platform facies reflect relatively shallow sedimentary water bodies. It may experience temporary subaerial exposure and erosion. Gray thin-bedded micritic limestones of open platform facies reflect relatively deep sedimentary water bodies. The change of lithology above or below the boundary reflects the change of the relative sea level. Therefore, the lithology and lithofacies transformation boundary is served as a sequence boundary.

\section{Sequence stratigraphic division and correlation}

The Jialingjiang Formation is divided into third-order sequences ( $\mathrm{Sq} 1, \mathrm{Sq} 2$, and $\mathrm{Sq} 3$ ) and six systems tracts (Catuneanu 2017) from bottom to top. The T1j1 and T1j2 constitute the $\mathrm{Sq} 1 ; \mathrm{T} 1 \mathrm{j} 3$ and $\mathrm{T} 1 \mathrm{j} 4$ constitute the $\mathrm{Sq} 2 ; \mathrm{T} 1 \mathrm{j} 5$ constitute the Sq3. Each third-order sequence boundary of this well is the exposure unconformity surface, which corresponds to the stratigraphic interface. Because of subarial exposure, there is obvious sedimentary facies change along the sequence boundary. The boundary is at the bottom or top of these facies. In accordance with relative sea-level fluctuation, each sequence can be divided into two parts, which includes transgressive systems tracts (TST) and highstand systems tracts (HST) (Fig. 4). The marine flooding surfaces between TST and HST of each sequence are mainly based on the variation of logging curve, which correspond to high natural gamma values and low apparent resistivity values.

The length of connecting-well profile is nearly $500 \mathrm{~km}$. This profile extends southwest to northeast, and the deposition thickness is 350-1100 m (Fig. 5). The thickness of the Jialingjiang Formation significantly changes in each sequence. The strata are thick in the northeast and thin in the southwest (Fig. 4). During the Sq1, the thickness of the strata is gradually become thick from the southwest to the northeast. During the TST of Sq1, the overall thickness varies little except in well Laolong 1, Wei 68 and Wei 14. During the HST of Sq1, the overall thickness varies little except in well She1. The thickness of the HST is thinner than the TST. During the Sq2, the thickness of the strata is gradually becoming thick from the well Yunhe 4. During the TST of $\mathrm{Sq} 1$, the overall thickness varies little. During the HST of Sq1, the overall thickness varies little except in well Yunhe 4 and She1. The thickness of the HST is thicker than the TST. During the Sq3, the thickness of the strata is thinner in well Laolong 1 and She1. During the TST of Sq1, the overall thickness varies little except in well Wei 14. During the HST of Sq1, the overall thickness is thin in the west and thick in the central and northeast of the basin. The thickness of the HST is thicker than the TST. Subsidence centers are located in Central and Northeast Sichuan subdepression, where the thickness is up to $1050 \mathrm{~m}$. Laterally, the thickness of the

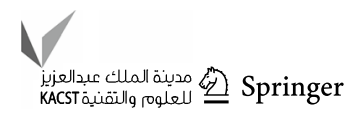


strata in well Moshen 1, Nvshen 5, and Yunhe 4 increases, and is influenced by sedimentation due to denudation in the northeastern part of the basin as a result of the tectonic uplift in the Late Permian Changxing and Jialingjiang Formations (Tan et al. 2011; Jiang et al. 2014; Wang et al. 2015).

During the early Triassic, the tectonic environment was relatively stable, and the regional sedimentary environment did not change, so correlation of systems tracts is good. During the transgression (TST), oolitic shoals and intraplatform shoals are developed in the eastern and middle portions of the Sichuan Basin. During the HST, evaporitic platform and dolomite flats are developed in the northern and northeastern portions of the Sichuan Basin. The distribution of oolitic shoals and dolomite reservoirs has implications for gas exploration and development in the Jialingjiang Formation.

\section{Sedimentary facies distribution and basin evolution}

Three large-scale transgressive-regressive events were recorded from the Jialingjiang Formation. The sedimentary evolution of the Jialingjiang Formation can be divided into three major periods according to the sequence stratigraphic division, including sedimentary systems tract of Sq1, Sq2, and Sq3. each period contains both TST and HST. In the Jialingjiang Formation, the sedimentary characteristic of each period exhibited a shallowing-upward trend and also a complete transgressive-regressive cycle (Wang et al. 2015).

Before the deposition of the Jialingjiang Formation, the basin did not change geomorphically with the relative sealevel rising. The sedimentary facies changed obviously in the TST of the Sq1. Mixed tidal flat facies were developed in southwestern part of the basin. Restricted lagoon facies were developed along the Guangyuan and Chengdu areas. Open platform was developed in the central and eastern parts of the basin, and most of which was covered by oolitic shoals (Fig. 6a). During the HST of Sq1, the basin developed mainly mixed tidal flat, restricted lagoon and restricted tidal flat facies from the east to west. The distribution of mixed tidal flat facies was relatively narrow. In the Tongnan and Dianjiang areas, evaporitic platform sporadically was developed (Fig. 6b). The sedimentary stage of the TST of Sq2 coincided with the development of restricted platform and open platform (Fig. 6c). As the transgression culminated, the scale of the intraplatform shoal deposits continued to expand. During the HST of Sq2, marine regression influenced the development of restricted platform in the entire area. Small-scale evaporitic platform and intraplatform shoal were also deposited (Fig. 6d). During the sedimentary stage of the TST of Sq3, the evaporitic platform, restricted platform, and open platform were developed from the west to east as the relative sea-level rising. Open platform shoal facies were locally deposited in eastern part of

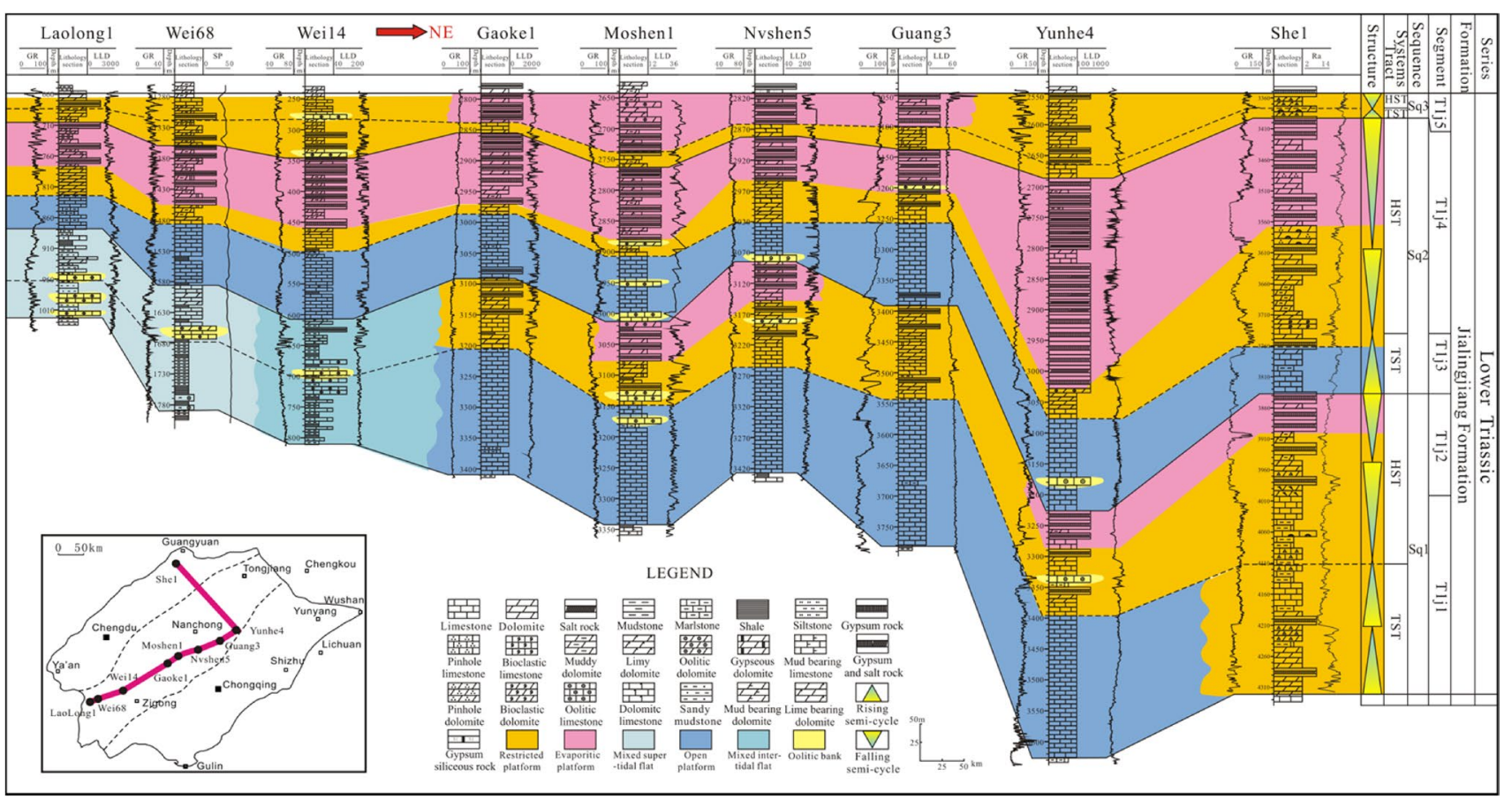

Fig. 5 Profile of sedimentary facies and sequence stratigraphic correlation in the Jialingjiang Formation, Sichuan Basin

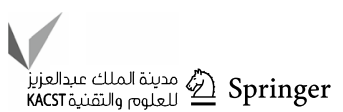



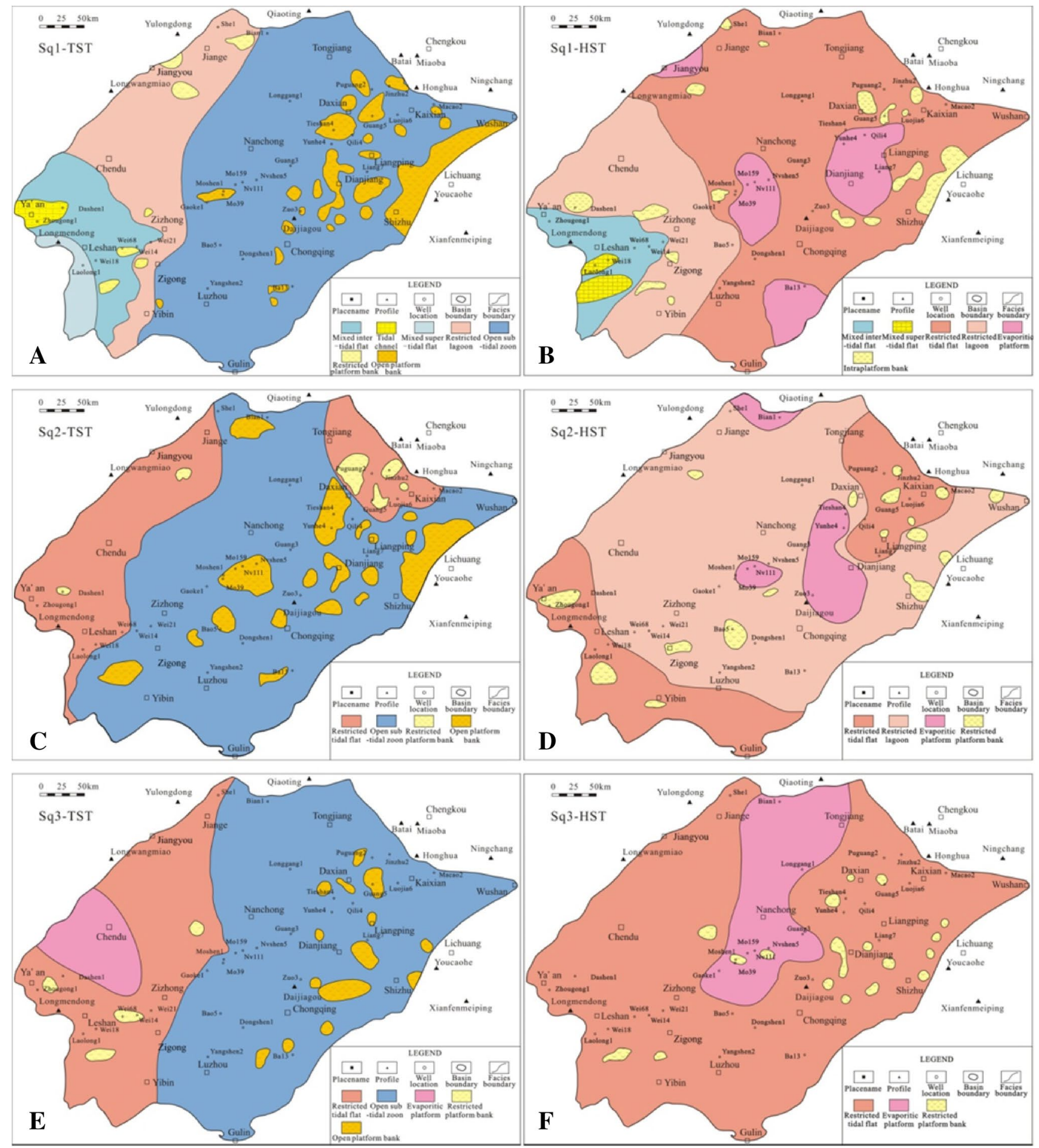

Fig. 6 Sedimentary facies distribution of different stages in the Jialingjiang Formation, Sichuan Basin 
the basin (Fig. 6e). Furthermore, the restricted tidal flat was widely distributed in the HST of Sq3, and evaporitic platform was common in the Tongnan and Nanchong areas (Fig. 6f).

\section{Reservoirs characteristics and controlling factors}

Economically important reservoirs of the Jialingiiang Formation in the Sichuan Basin were represented by oolitic limestone and algal dolomite. Shoals and restricted tidal flat were significant favorable reservoir units in the Sichuan Basin. Detailed examination afforded an unambiguous demonstration of carbonate platform sedimentary mode (Tan et al. 2011). The sedimentary model could predict the scale of oolitic shoals and dolomite flats, their depositional features, distribution law, and associated connectivity (Fig. 7). Oolitic shoals within the open platform distributed in the eastern and central of the basin and dolomite flats within the restricted platform distributed in northeastern basin had oolitic limestone and dolomite with relatively good-quality physical properties (Mzzullo and Harris 1992), which represented favorable reservoir facies belts of hydrocarbon accumulation, and might be the next potential reservoir targets for exploration.

The porosity of these reservoirs ranged from 0.02 to $22.64 \%$, and the permeability was generally less than 0.001 md in the Jialingjiang Formation of the Sichuan Basin. The effective thickness of reservoir was between 0 and $22.08 \mathrm{~m}$. The physical data indicated that reservoirs porosity and permeability in the Jialingiiang Formation of the Sichuan Basin was generally low. According to the detail observation of drilled cores from wells and outcrop sections in the study area, logging comprehensive interpretation results, coupled with physical properties analysis of core section with hydrocarbon display, it was considered that the oolitic limestone and algal dolomite reservoirs in the Jialingjiang Formation were given priority to middle-to-low porosity and low permeability.

According to the characteristics of reservoir lithology and diagenesis, it could be concluded that sedimentary facies, dissolution, and dolomitization were the key-controlling factors of reservoirs (Thanguay and Friedman 2001; Li et al. 2008; Tan et al. 2011; Jiang et al. 2014; Wang et al. 2015). Sea-level fluctuations created or destroyed accommodation space. Deposition range of different facies varied through each transgressive-regressive cycle. The open platform controlled the distribution and development of oolitic limestone reservoirs, and the restricted platform controlled the distribution and development of dolomite reservoirs. Dissolution and dolomitization were favorable for the formation of secondary porosity and could improve pore connectivity and permeable conditions, and thereby made the physical properties of reservoirs better.

\section{Conclusion}

The Lower Triassic Jialingjiang Formation in the Sichuan Basin represented a marine carbonate platform facies system, with four types of facies including mixed tidal flat facies, open platform facies, restricted platform facies, and evaporitic platform facies that could be subdivided into multiple subfacies and microfacies.

The Jialingjiang Formation contained two types sequence boundaries, including unconformity boundary and lithology and lithofacies transformation boundary. On the basis of the three transgressive-regressive cycles, the Jialingjiang Formation was divided into three third-order sequences and six systems tracts, with each sequence showing a shallowingupward trend.

The sedimentary facies of the Jialingjiang Formation changed obviously from west to east and was controlled by tectonics and sea level. Sedimentary stage of the TST

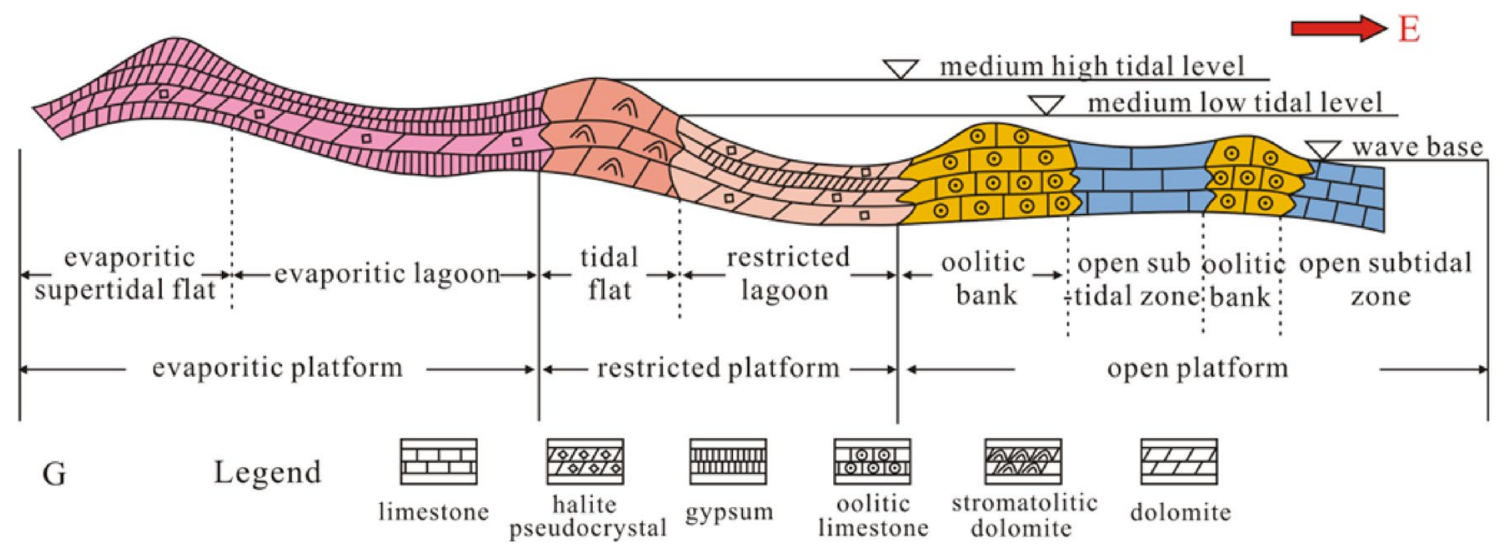

Fig. 7 Sedimentary model of carbonate platform in the Jialingjiang Formation, the Sichuan Basin

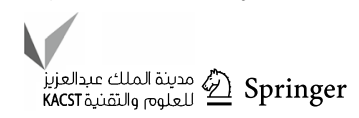


mainly developed in open platform. During this stage, the eastern and central part of the basin developed oolitic shoal reservoirs. In the HST, the sedimentary range of restricted platform expanded with strong regression. The northeastern basin during this stage developed good-quality dolomitic reservoirs. Restricted platform dolomite flats and open platform oolitic shoal had algal dolomite and oolitic limestone with relatively well physical properties, and were the major hydrocarbon-bearing reservoir facies belt, which might be the next potential reservoir targets for exploration of the Jialingjiang Formation.

Acknowledgements This study was supported by the National Natural Science Foundation of China (Grant Nos. 41372126, 41772103) and the National Science and Technology Major Project of China (Grant No. 2016ZX05007-002).

Open Access This article is distributed under the terms of the Creative Commons Attribution 4.0 International License (http://creativeco mmons.org/licenses/by/4.0/), which permits unrestricted use, distribution, and reproduction in any medium, provided you give appropriate credit to the original author(s) and the source, provide a link to the Creative Commons license, and indicate if changes were made.

\section{References}

Catuneanu O (2017) Sequence stratigraphy: guidelines for a standard methodology. Stratigr Timescale 1-57. https://doi.org/10.1016/ bs.sats.2017.07.003

Ehrenberg SN (2006) Porosity destruction in carbonate platforms. J Petrol Geol 29:41-52

Enos P, Sawatsky LH (1981) Pore networks in Holocene carbonate sediments. J Sed Petrol 51:961-986

Flügel E (2010) Microfacies of carbonate rocks: analysis, interpretation and application, 2nd edn. Springer, Berlin, pp 575-586

Harris PM (2010) Delineating and quantifying depositional facies patterns in carbonate reservoirs: insight from modern analogs. AAPG Bull 91:61-86

Jiang L, Worden RH, Cai CF (2014) Thermochemical sulfate reduction and fluid evolution of the Lower Triassic Feixianguan Formation sour gas reservoirs, northeast Sichuan Basin, China. AAPG Bull 98:947-973

Li HT (2016) Accumulation process and pattern of oolitic shoal gas pools in the platform: a case from Member 3 of Lower Triassic Feixianguan Formation in the Heba area, northeastern Sichuan Basin. Petrol Explor Dev 43:787-797

Li P, Zou H, Zhang Y, Wang C, Zhang X (2008) Paleo-oil-water contact and present-day gas-water contact: implication for evolution history of Puguang Gas Field, Sichuan Basin, China. J Earth Sci 19:715-725

Mancini EA, Benson DJ (1998) Sequence stratigraphic controls on carbonate shoal and reef reservoir architecture and heterogeneity; Upper Jurassic Smackover Formation, northeastern Gulf of Mexico. AAPG Bull 82:19-38

Mzzullo SJ, Harris PM (1992) Mesogenetic dissolution: its role in porosity development in carbonate reservoir. AAPG Bull 76:607-620

Pomar (2001) Types of carbonate platforms: a genetic approach. Basin Res 13:313-334

Read JF (1985) Carbonate platform facies models. AAPG Bull 69:1-21

Tan XC, Li L, Liu H et al (2011) General depositional features of the carbonate platform gas reservoir of the Lower Triassic Jialingjiang Formation in the Sichuan Basin of southwest China: Moxi gas field of the central basin. Carbonate Evaporite 26:339-350

Thanguay LH, Friedman GM (2001) Petrophysical characteristics and facies of carbonate reservoirs: the red river formation (Ordovician), Williston Basin. AAPG Bull 85:491-523

Tian DX (1989) Sedimentary characteristic in the second member of Jialingjiang Formation of Lower Triassic in the center of Sichuan Basin. Oil Gas Geol Mar Depos Reg 3:50-55

Vail PR, Michum RM, Thonoson S (1977) Seismic stratigraphy and global changes of sea level, Part 4: global cycles of relative changes of sea level. In: Payton CE (ed) Seismic stratigraphyapplication to hydrocarbon exploration, vol. 26. AAPG Mem, New York, pp 83-97

Wang MQ, Zhao YJ, Liu CL, Ding T (2015) Paleotemperature and sinificance of the evaporated sea water in salt-forming process of the forth member of Jialingjiang Formation in the eastern Sichuan Basin. Acta Petrol Sin 31:2745-2750

Publisher's Note Springer Nature remains neutral with regard to jurisdictional claims in published maps and institutional affiliations. 